\title{
Dissociable Effects of Kappa-Opioid Receptor Activation on Impulsive Phenotypes in Wistar Rats
}

\author{
Brendan M Walker,', and Jessica L Kissler' \\ 'Laboratory of Alcoholism and Addictions Neuroscience, Department of Psychology, Graduate Program in Neuroscience, Washington State \\ University, Pullman, WA, USA
}

\begin{abstract}
The kappa-opioid receptor (KOR) is the primary target for the endogenous opioid peptide dynorphin (DYN), and KORs reside within brain circuitry underlying the complex integration of information related to different behavioral domains such as motivation, negative affect, and decision-making. Alterations in extended amygdala DYNs and KOR function following chronic alcohol exposure have been shown to mediate escalated alcohol self-administration during acute withdrawal. In addition to excessive alcohol consumption and increased negative affect, other symptoms of alcohol dependence include compromised impulse control. Given that DYN and KOR expressions are dysregulated within prefrontal brain circuitry associated with decision-making and impulse control in alcoholdependent humans and rodents, and have been shown to modify multiple neurotransmitter systems associated with impulse-control disorders, we hypothesized that KOR activation could contribute to impulsive phenotypes. To test this hypothesis, separate cohorts of male Wistar rats were trained in one of the two animal models of impulsivity: delay-discounting (DD) or stop-signal reaction time (SSRT) tasks, and once stable responding was observed, received intracerebroventricular (ICV) infusions of the KOR agonist U50,488 $(0-50 \mu \mathrm{g})$ according to a within-subject dosing regimen. The results demonstrated a dissociable effect of U50,488 on impulsive phenotypes related to intolerance to delay or response inhibition, with selective effects in the SSRT. Furthermore, the pro-impulsive effects of KOR activation were rescued by pretreatment with the KOR antagonist nor-binaltorphimine (nor-BNI). Therefore, KOR activation was shown to induce an impulsive phenotype that was nor-BNI-sensitive. Dysregulation of impulsive behavior by increased DYN/KOR activity could serve to increase vulnerability for the initiation, or perpetuate existing patterns of excessive alcohol abuse and can enhance the probability of relapse in dependent individuals. Furthermore, KOR-mediated impulsivity has implications for numerous neuropsychiatric disorders.

Neuropsychopharmacology (2013) 38, 2278-2285; doi:I0.1038/npp.20 I3.I29; published online I2 June 20I3
\end{abstract}

Keywords: alcohol; dependence; delay-discounting; impulsivity; kappa-opioid receptor; stop-signal reaction time task

\section{INTRODUCTION}

In 2005, the 12-month prevalence rate for alcohol use disorders (AUDs) in US adults aged $\geqslant 18$ years was $\sim 7.9 \%$, with $3.4 \%$ being diagnosed as alcohol-dependent (Substance Abuse and Mental Health Services Administration, 2005). There is significant comorbidity between AUDs/alcohol dependence and affective disorders (for example, see Grant and Harford, 1995), with up to $33 \%$ of those classified as alcoholic also experiencing major depression (Roy et al, 1991), the etiology of which has been shown to be partially alcohol-induced (Schuckit et al, 1997a). Indeed, it has been suggested that some individuals may use alcohol to 'selfmedicate' their negative affective symptoms (see Williams

*Correspondence: Dr BM Walker, Laboratory of Alcoholism and Addictions Neuroscience, Department of Psychology, Graduate Program in Neuroscience, Washington State University, Mail Code: 644820, Pullman, WA 99|64-4820, USA, Tel: +509 3358526 , Fax: +509 335 5043, E-mail: brendan.walker@wsu.edu Received 21 March 2013; revised 7 May 2013; accepted 8 May 2013; accepted article preview online 21 May 2013 et al, 2012 for an in-depth focus on this issue). Additional phenotypes of alcohol dependence include heightened impulsivity and reduced cognitive flexibility (FernandezSerrano et al, 2011) that, in combination with negative affective states and the plasticity-dependent process of negative reinforcement learning (Walker, 2012), perpetuate the cycle of intoxication and withdrawal that characterizes those afflicted with alcohol dependence. Collectively, these factors promote a loss of inhibitory control and drive excessive alcohol consumption (for example, see Roberts et al, 2000).

Recent evidence confirmed a role for dynorphin (DYN)/ kappa-opioid receptors (KORs) in escalated alcohol consumption in both non-dependent (Berger et al, 2013) and alcohol-dependent rats (for review, see Walker et al, 2012), depressive phenotypes (for example, see Todtenkopf et al, 2004), and the dysphoria produced by stress (Land et al, 2008). Furthermore, selective antagonists for the KOR have antidepressant properties in naive and alcohol-dependent rats during withdrawal (Mague et al, 2003; Berger et al, 2013), and have been shown to reduce escalated alcohol 
self-administration in dependent animals (Walker and Koob, 2008; Walker et al, 2011; Nealey et al, 2011). The dynamic nature of the DYN/KOR peptide system has also been demonstrated by showing that KOR mRNA was increased in the basolateral, but not in the central nucleus of the amygdala $(\mathrm{CeA})$ of rats during fear conditioning and that following extinction to the conditioned stimulus, KOR mRNA levels returned to baseline (Knoll et al, 2011). However, the problem remains that not only are there no FDA-approved treatments for the negative affect that accompanies alcohol dependence (Heilig and Koob, 2007), but also the role of the DYN/KOR system in the complex integration of impulsive and negative affective behavior is only beginning to be understood.

Alterations in DYN/KOR systems contribute to excessive alcohol seeking and consumption (Walker and Koob, 2008; Walker et al, 2011; Nealey et al, 2011; Kissler et al, 2013). KORs are located in brain circuitry, mediating negative affect, decision-making, emotion, learning, motivation, and pain (Mansour et al, 1994; Mansour et al, 1987). In alcoholdependent humans and rodents, upregulation of DYN/KOR system occur within nuclei comprising the central extended amygdala (Nealey et al, 2011; Kissler et al, 2013), dorsolateral prefrontal cortex (dlPFC in humans is considered analogous to the rat ventromedial (vm) PFC), and orbitofrontal cortex (OFC) (Bazov et al, 2013) that have traditionally been proposed to regulate specific types of behaviors (for example, the dlPFC regulates decision-making and the amygdala regulates emotion). Conversely, contemporary perspectives (for example, see Goldstein et al, 2007; Pessoa et al, 2012) posit that these brain regions participate in the complex integration of information related to different behavioral domains (for example, the dlPFC is a site of integration for decision-making and negative affect) that when dysregulated by chronic alcohol exposure, could contribute to phenotypes that are hallmarks of alcohol dependence (for example, excessive alcohol consumption, heightened impulsivity, increased negative affect, decreased cognitive flexibility, and impaired inhibitory control; for review, see Crews and Boettiger, 2009). An excellent example of such integration are the results demonstrating dlPFC engagement during response inhibition following negative valence induction, although the dlPFC was not recruited by either response inhibition or negative valence induction alone (Goldstein et al, 2007), which indicated that it was only the combination of stimuli that recruited the dlPFC under those particular conditions.

One of the criteria for alcohol dependence in the DSM-IV TR is a 'continued substance use despite having persistent or recurrent social or interpersonal problems' (American Psychiatric Association, 2000). This definition is suggestive of an inability to inhibit actions, which results from dysfunctions in prefrontal regions in the brain (Winstanley, 2007; Cardinal, 2006). This lack of behavioral inhibition, or impulsiveness, is a behavioral trait observed in both humans and animals (Dougherty et al, 2009; Evenden and Ryan, 1996). Multiple constructs have been used to define impulsive behavior (Winstanley et al, 2006), and examples of those different approaches to assess impulsivity, broadly defined as action without foresight, include the delay-discounting (DD) task that measures intolerance to delayed rewards and the stop-signal reaction time (SSRT) task that measures the ability to inhibit a previously initiated action when provided a stopsignal (Ainslie, 1975; Mazur, 1989; Eagle and Robbins, 2003a,b). Compromised impulse control has been confirmed in alcohol-dependent subjects when assessing the ability to inhibit already initiated actions (for example, Schmaal et al, 2013), but has not been demonstrated using animal models. However, it is currently unknown whether alcohol dependence alters impulsive-like behavior via a KOR mechanism.

Given that in deceased alcoholics, DYN A and B, as well as mRNA for KORs were upregulated in the dlPFC and OFC, respectively, when compared with controls (Bazov et al, 2013), and preclinical evidence corresponds well, showing upregulated Pdyn gene expression in the prefrontal cortex following repeated alcohol administration (D'Addario et al, 2013); the extent to which upregulated DYN and/or increased KOR-mediated signaling directly contributes to maladaptive behavioral regulation associated with alcohol dependence is unclear. To address this issue and test the hypothesis that KOR-mediated signaling contributes to impulsive phenotypes, the KOR agonist U50,488 was infused centrally to 'mimic' a withdrawal state in alcoholdependent animals (Berger et al, 2013) in order to assess the effects of U50,488 on the performance of animals in the DD and stop-signal reaction time (SSRT) tasks. It is important to note that using a neuropsychopharmacological approach affords a greater level of control in this initial investigation. Of particular relevance to the present investigation are assertions that performance in the DD task best predicts binge behavior, whereas performance in the SSRT better represents an alcohol-dependent state (for review, see Aragues et al, 2011), a proposition based, in part, on a dissociable neurobiology underlying the two tasks (de Wit, 2009). If that profile should be realized in the present study using KOR agonists to 'mimic' an alcohol-dependent withdrawal state, confidence in the construct validity of the model would be increased. Critical to such an interpretation is the fact that the involvement of the DYN/KOR system has not been implicated in alcohol bingerelated behaviors using genetically selected high-drinking lines of rodents (Sabino et al, 2011; Deehan, et al, 2012), whereas alcohol-dependence-related phenotypes have been shown to involve neuroadaptations in the DYN/KOR system (Walker and Koob, 2008; Walker et al, 2011, 2012; Nealey et al, 2011; Sirohi et al, 2012; Berger et al, 2013; Kissler et al, 2013).

\section{MATERIALS AND METHODS}

\section{Animals}

Eighteen male Wistar rats $\sim 70$ days old were pair-housed in an environmentally controlled vivarium on a reverse light cycle (lights off at 0600 hours). The animals were placed on a restricted diet designed to maintain the animals at $\sim 85-90 \%$ of their free-feeding weight while allowing for growth to occur, with water available ad libitum. All work adhered to the National Research Council's Guide for the Care and Use of Laboratory Animals(National Research Council, 1996) and was approved by the WSU Institutional Animal Care and Use Committee. 


\section{Apparatus and Acquisition of the Operant Response}

All training and testing for the DD and SSRT procedures were conducted in 12 standard operant conditioning chambers in sound/light-attenuating boxes (Med Associates, St Albans, VT). To acquire the lever-pressing behavior, food-restricted rats were placed in the operant chambers on continuous reinforcement schedule for up to $4 \mathrm{~h}$ or when 150 responses were recorded (whichever came first) for 3 consecutive days.

\section{DD Training}

The DD task measures the ability to tolerate delay to reinforcement by providing access to a large and small reinforcer (four $v s$ one $45-\mathrm{mg}$ sucrose pellet), with a delay to obtain the large reinforcer progressively increasing as the trial continues. During a given session, a point will be reached for which the animal shows equal preference for the small and large reinforcer, the indifference point. Increases in the percentage of small reward choice would be indicative of increased impulsive responding. Human alcoholics will discount delayed rewards at a faster rate than both abstinent, and non-alcoholic controls, which supports the theory that dependent states will increase impulsive choice, though no known preclinical research confirms this (Petry, 2001).

Following operant training, DD training began by exposing the animals to two levers (counterbalanced for side), with one providing a single $45-\mathrm{mg}$ sucrose pellet and the other four sucrose pellets as reinforcement. Subsequently, the lever would immediately retract and the reinforcer would be deposited into the trough with zero delay of reinforcement and a 5-s inter-trial interval (ITI) before the beginning of the next trial and lever extension. The criterion for acceptable performance was $80 \%$ large reinforcer choice over three sessions.

The next set of training sessions was a modification of the within-session DD model (see Evenden and Ryan, 1996). The 60 trial session was divided into six blocks of 10 trials. The first two trials in each block were termed 'forced trials' where both levers were extended but only one of the levers was active (that is, delivered a food reinforcer). Forced trials were implemented to expose the rat to each reward contingency prior to having the choice during the eight remaining 'free trials'. Within each block, the large reinforcer lever was associated with a temporal delay $(0,1,2,4,8$, and $10 \mathrm{~s})$ between lever-press and reinforcer delivery. Rats continued on this schedule until their mean responses for each block did not deviate $>20 \%$. Once stable, the animals progressed to the final training stage in which the delays to reinforcer delivery were increased $(0,2$, $4,8,10$, and $20 \mathrm{~s}$ ). The animals continued on this stage until the above criterion was met, and then the animals underwent surgery and pharmacological manipulations (see below). Increased impulsivity in the DD task is represented by a reduction in the percent of large reinforcer choice, without increased omissions (sign of reduced motivation), presumably due to an organism's inability to tolerate the increasing delay of the large reinforcer.

\section{Stop-Signal Reaction Time Training}

The SSRT task is designed to assess the ability of an animal to withhold an operant response that has already been initiated when cued to do so. Initial training in a two-lever operant chamber involved responding on the one lever to induce the extension of the alternate lever. In order to receive a reinforcer, a rat must press the second extended lever within $20 \mathrm{~s}$, or that trial will be counted as an omission. On $20 \%$ of the trials, the stop-signal (inverted house light on the wall between the two levers) was illuminated upon pressing the initial lever. If a response is made on the second lever after the stop-signal is presented, it was counted as a 'Miss' and the rat will receive a 10-s non-reinforced time out. However, if a rat correctly withholds responding for $5 \mathrm{~s}$, this will be scored as a 'Hit'. By altering the amount of time between the stop-signal and the final response (that is, the stop-signal delay; SSD), the percentage of correct responses will decrease as the SSD increases and approaches the mean reaction time to respond in a non-stop-signal trial $(\sim 930 \mathrm{~ms}$ in our cohort) (Eagle and Robbins, 2003a,b). Increased impulsivity in the SSRT task is characterized by a reduction in the correct 'Hit' rate, without increased omissions (sign of reduced motivation) or decreased total responding (sign of possible locomotor effects).

The rats were trained to lever press for the SSRT task identically to that of the aforementioned DD task. Once stable lever pressing (three consecutive trials with $<10 \%$ deviation and $>80 \%$ correct hits) was achieved, a lever-press on the first extended lever would result in its retraction and the immediate extension of the second lever. A press on the right lever would result in the delivery of a single $45-\mathrm{mg}$ sucrose pellet, the lever would then retract, and following a 5-s ITI the left lever would extend again, initiating the next trial. If an animal failed to respond at any point for $20 \mathrm{~s}$, the extended lever would retract and that trial would be scored as an 'omission'. All rats remained on this task until a mean of $80 \%$ correct responses (160 of 200 trials) was achieved. The final training stage included a random stop-signal (an inverted house light located directly above the food trough) on $20 \%$ ( 40 of 200 ) of the trials. On the stop-signal trials, a correct 'hit' response was recorded if the stopsignal was illuminated immediately after the initial lever press, and the rat did not press the second lever. An incorrect 'miss' was recorded if the stop-signal was illuminated and the rat completed the response, at which point levers retracted and a 10-s time out with no reinforcer delivery was initiated. All rats continued on this stage until they achieved a mean of 32 correct hit responses out of the 40 stop-signal trials, at which point the animals underwent surgery (see below).

\section{Surgical Procedures}

Once stable responding was achieved, rats were anesthetized and bilaterally implanted with intracerebroventricular (ICV) guide cannulae according to stereotaxic coordinates (AP - 0.8, ML $\pm 1.5, \mathrm{DV}-3$, from bregma; Paxinos and Watson, 2007). Animals received postoperative antibiotics (Baytril) and flunixin (a non-narcotic, non-steroidal analgesic agent with anti-inflammatory properties) for 5 days following surgery.

\section{Pharmacology}

The animals were allowed to recover prior to continued training until stable responding was again achieved (three 
consecutive trials, with $<10 \%$ deviation and $>80 \%$ correct hits for the SSRT or $80 \%$ large reinforcer lever-presses for the DD task) following ICV aCSF infusions that occurred 5 min prior to the training sessions. The KOR agonist U50,488 (0, 0.25, 2.5, and $50 \mu \mathrm{g}$ total dose; Tocris Biosciences) was infused according to a within-subject Latin square design $5 \mathrm{~min}$ prior to DD test trials that included a $0-, 2-, 4-, 8-, 10-$, or 20-s delay to a large reinforcer or seven consecutive SSD trials $(\mathrm{SSD}=0,130$, $230,330,430,530,630$, and $730 \mathrm{~ms}$ ) that were randomly presented and introduced once stable aCSF-treated responding on the SSD 0 delay occurred. Following a 2-week restabilization period for the SSRT animals (see criterion above), they were tested in the SSRT under conditions of aCSF and aCSF + U50,488 $(0.25 \mu \mathrm{g})$, according to a counterbalanced within-subject design with SSD intervals as described above. Subsequently, a single dose of the KOR antagonist nor-binaltorphimine (nor-BNI, $8 \mu \mathrm{g}$; Tocris Biosciences) was infused ICV because nor-BNI has previously been shown to have an extended duration of action (Bruchas et al, 2007) that allows for repeated testing following just a single administration (Walker et al, 2011; Chartoff et al, 2012). The animals were then tested in the SSRT under the following conditions: nor-BNI + aCSF and nor-BNI + U50,488 $(0.25 \mu \mathrm{g})$ according to a counterbalanced within-subject design, with SSD intervals as described above. All infusions were $1 \mu \mathrm{l} /$ side over $74 \mathrm{~s}$ and separated by at least $48 \mathrm{~h}$. U50,488 dosing was based on Bals-Kubik et al, 1989, with slight modifications and nor-BNI dosing on our previous work (for example, Walker and Koob, 2008; Berger et al, 2013). Histological analysis confirmed the accurate placement of the intraventricular guide cannulae.

\section{Statistical Analysis}

All data sets (that is, DD, SSRT/U50,488 dose-response, and SSRT/nor-BNI + U50,488) were analyzed with a two-way within-subject analysis of variance (ANOVA) with pharmacological challenge condition and delay interval or SSD as the within-subject variables. If main effects or interactions were identified, post-hoc least significant differences (LSD) tests were conducted. In addition, the SSRT/U50,488 average hit rates were evaluated by one-way repeated measures ANOVA, with post-hoc LSD tests conducted if a main effect of U50,488 dose was found. In all cases, statistical results were only accepted if they reached significance $(\alpha=0.05)$ with power $>0.8(\beta=0.2)$.

\section{RESULTS}

As seen in Figure 1, all animals increasingly discounted the large reinforcer as the delay interval was increased $(\mathrm{F}(5,30)=54.138, P<0.001)$, but there was no main effect of U50,488 dose on DD performance $(F(3,18)=2.469$, $P>0.05)$, as there was no interaction $(\mathrm{F}(15,90)=0.65$, $P>0.05)$. Importantly, these effects were not due to any type of motivational deficits produced by U50,488, as the rate of omissions stayed low ( $<3$ omissions).

Conversely, as seen in Figure 2, the KOR agonist U50,488 dose dependently increased impulsive responding, as evidenced by a reduction in the number of correct response
Effects of the KOR Agonist U50,488 in the Delay Discounting Paradigm

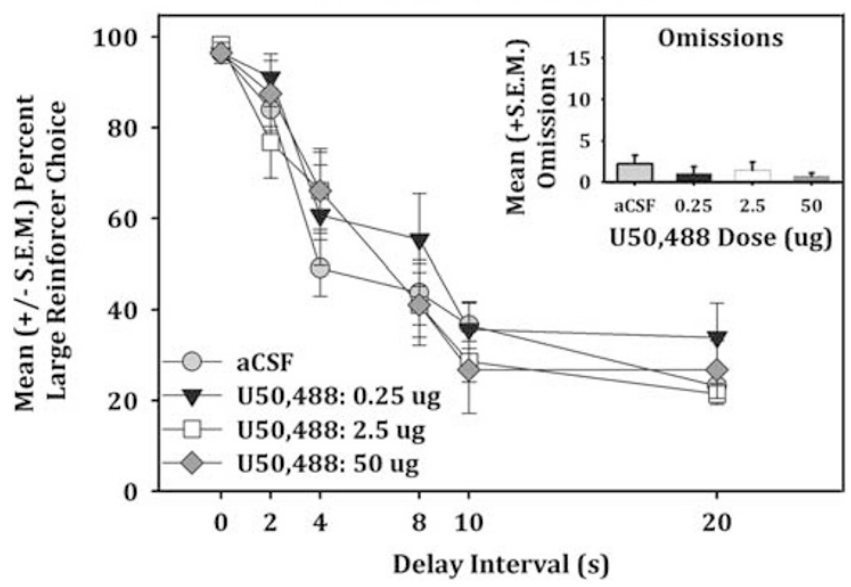

Figure I Mean $( \pm$ SEM) performance in the delay-discounting task following exposure to different doses of the kappa-opioid receptor agonist U50,488. No effect of U50,488 on impulsive-like behavior related to intolerance to delay that cannot be accounted for by changes in omissions (see inset).

The KOR Agonist U50,488 Reduces the Capacity to Inhibit Previously Initiated Actions

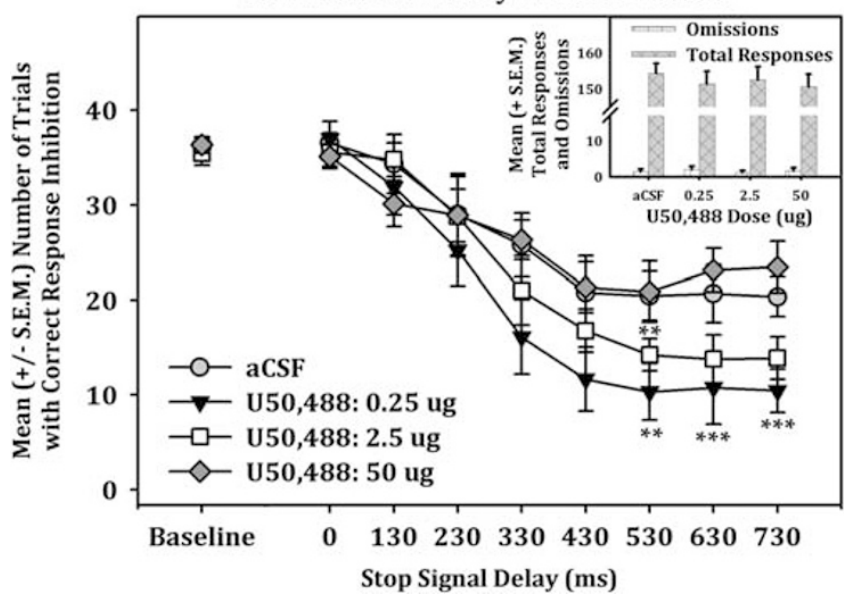

Figure 2 Mean $( \pm S E M)$ correct response inhibition in the stop-signal reaction time task following pretreatment with the KOR agonist U50,488 $(n=9 /$ dose). The number of trials with correct response inhibition was significantly reduced ( ${ }^{* *} P \leqslant 0.01$; ${ }^{* * *} P \leqslant 0.001$ when compared with aCSFtreated trials), although omissions and total response rate were unaffected (see inset).

inhibition trials compared with aCSF. A two-way withinsubject ANOVA conducted on the hit rate identified a main effect of dose $(\mathrm{F}(3,24)=6.168, P>0.01$, power $=0.929)$ and a main effect of SSD $(F \quad(7,56)=23.493, P<0.01$, power $=1.0)$. The effects of dose had a quadratic relationship $(\mathrm{F}(1,8)=15.147, P, 0.01$, power $=0.924)$. SSD dose had a linear relationship $(\mathrm{F}(1,8)=99.570, P<0.001$, power $=1.0$ ). Post-hoc comparisons showed that the $0.25-\mu \mathrm{g}$ dose of U50,488 significantly differed from aCSF-treated responding on the 530,630, and 730 SSD trials $(* * P<0.01$;

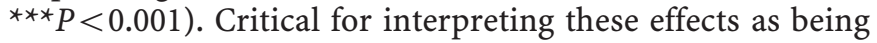
specific to impulsivity is the observation that omissions were not increased and total response rate was not decreased, indicating that motivation to engage in the task 
was intact and that there were no locomotor effects of the KOR agonists. Figure 3 demonstrates the U-shaped nature of the quadratic contrast identified in the previous analysis. The one-way ANOVA showed a significant main effect of U50,488 dose (Greenhouse-Geisser corrected F (1.16, $8.123)=10.678, P=0.01$, power $=0.847)$ with a significant quadratic contrast $(\mathrm{F}(1,7)=10.668, P=0.014$, power $=0.8)$. Post-hoc comparisons identified that the $0.25-$ and $2.5-\mu \mathrm{g}$ doses differed significantly from the aCSF condition $(P=0.002$ and 0.015 , respectively).

The two-way ANOVA conducted on the nor-BNI challenge data (see Figure 4) showed a significant main effect of Condition ( $F(3,24)=9.51, P<0.001$, power $=0.991)$, $\operatorname{SSD}(\mathrm{F}(7,56)=18.782, P<0.001$, power $=1.0)$, and $\mathrm{a}$ trend towards a significant dose $\times$ SSD interaction (F (14, $112)=2.063, P=0.145$, power $=0.891$ ). Post-hocs showed that the aCSF + U50,488 groups' performance significantly differed from aCSF at the 530,630, and 730 SSD intervals $(P<0.001)$ and that nor-BNI rescued that effect $(P \leqslant 0.001$ when nor-BNI was compared with U50,488).

\section{DISCUSSION}

For the first time, activation of the KOR was shown to be pro-impulsive, with dissociable effects in the DD and SSRT tasks. Specifically, performance in the SSRT was selectively affected by the KOR agonist in a nor-BNI reversible manner. Important for a determination of a KOR agonist-induced impulsive-like phenotype is the fact that neither omissions nor total response rates were altered in the SSRT by KOR agonist infusions, showing that neither motivation nor locomotion, respectively, were affected by U50,488. These data support the hypothesis that KOR activation can regulate impulsive phenotypes, an effect that was shown to be specific to response inhibition and that supports contemporary assertions that the SSRT paradigm has predictive validity for an alcohol-dependent state (Aragues et al, 2011). The present results also increase confidence in the construct validity of 'mimicking' an alcohol-dependent

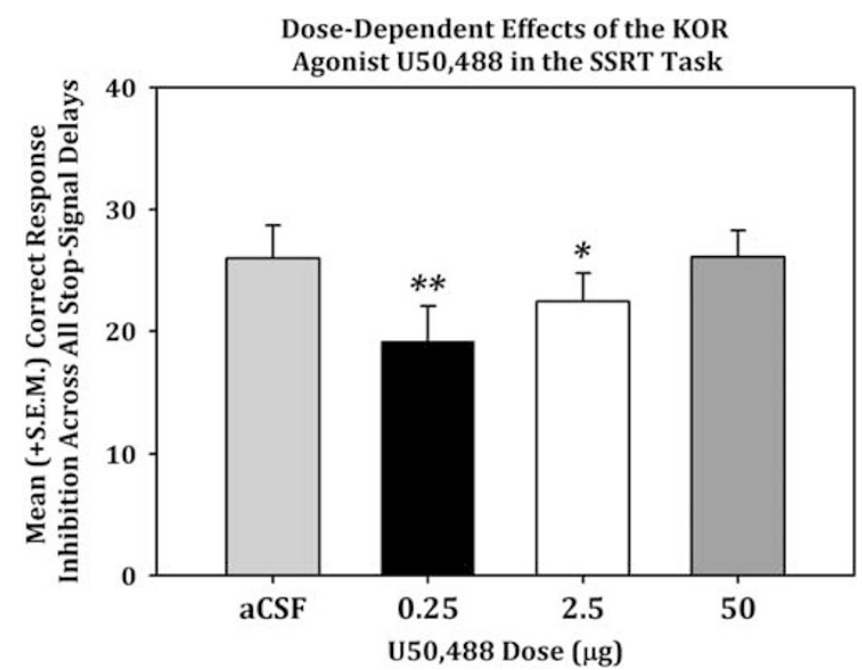

Figure 3 Mean (+SEM) correct response inhibition in the stop-signal reaction time task (SSRT), collapsed across all stop-signal delays. An $U$-shaped quadratic effect of $U 50,488$ was observed $(* P<0.05$; $* * P<0.0$ I when compared with aCSF condition). withdrawal state using KOR agonist infusions (Berger et al, 2013).

Of considerable interest is the fact that U50,488 showed a quadratic dose-dependent effect in the SSRT that is consistent with previous research, showing an U-shaped dose-response curve for U50,488 in the conditioned place aversion paradigm (Bals-Kubik et al, 1989). The interest lies in the apparent U50,488-mediated hedonic-like behavioral overlap with impulsive-like behavior and the fact that $P D Y N$, DYN A and B and OPRK1 are upregulated in brain regions not only heavily implicated in the cognitive control of decision-making and impulse control (Crews and Boettiger, 2009; Bazov et al, 2013; Winstanley, 2007), but also as integrators of affect and decision-making (Aragues et al, 2011), suggesting a novel PFC/OFC-based DYN/KOR target for therapeutics to treat impulse-control symptoms in dependence and possibly other neuropsychiatric disorders. The fact that nor-BNI did not reduce levels of impulsivity beyond baseline levels suggests that KOR ligands should show utility in treating conditions of reduced impulse control involving a dysregulated DYN/KOR system.

However, the current data are somewhat inconsistent with two previous studies, evaluating KOR activation (with U69,593 and salvinorin A, KOR agonists) in a 'cognitive' animal model (the attentional five-choice serial reaction time task) that showed motivational and possible locomotor effects of KOR agonists (Paine et al, 2007; Nemeth et al, 2010). Possible explanations for these differences are that (1) the present study assessed total lever pressing as an index of locomotor effects, whereas the previous studies saw the KOR agonist effects when assessing latency to respond, which might not have been captured using a total response measurement, (2) dose(s) of KOR agonists producing motivational and locomotor deficits were at a range unnecessary for cognitive investigations, or (3) quite possibly, there is a difference in effects of systemic and

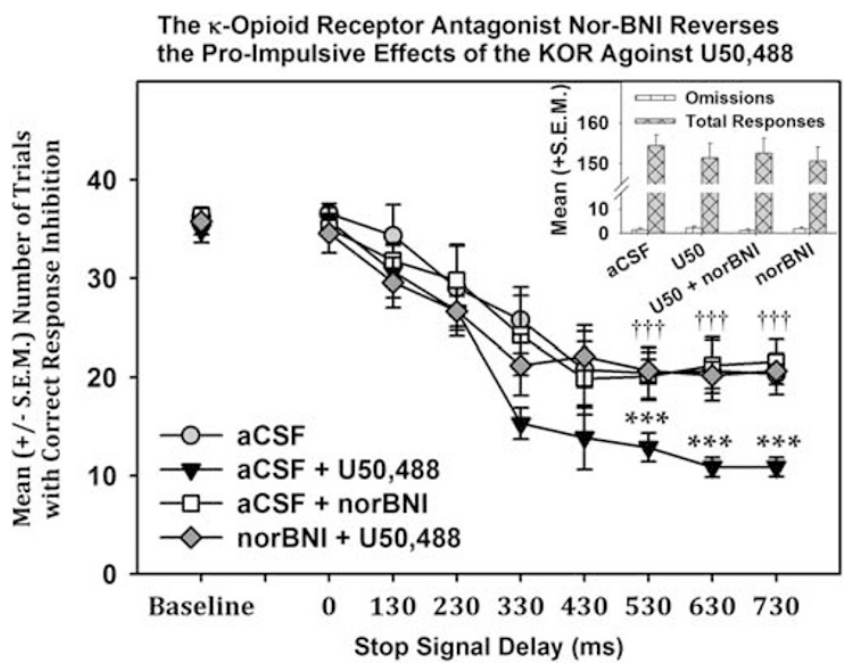

Figure 4 Mean $( \pm S E M)$ correct response inhibition in the stop-signal reaction time task following pretreatment with nor-BNI prior to KOR agonist U50,488 ( $n=9 /$ dose) infusion. The number of trials with correct response inhibition was significantly reduced (*** $P \leqslant 0.0$ I when compared with the artificial cerebrospinal (aCSF) condition) and nor-BNI rescued the KOR agonist-induced impulsive-like phenotype $\left({ }^{\dagger \dagger \dagger} P \leqslant 0.00\right.$ I when compared with the U50,488-treated trials) without producing an effect when administered alone or altering omissions or total responses (see inset). 
peripherally administered KOR agonists in motivational and locomotor domains. Further research will have to clarify these possibilities. Moreover, inconsistent with the present results were those determined by Mitchell et al (2005) that showed a pattern of results that were opposite to those of the present experiment, namely that abstinent alcoholics showed altered responsivity in a DD, but not a SSRT task. However, these differences can be easily reconciled by the fact that in the present study we were attempting to model alcohol dependence-induced acute withdrawal states, whereas the Mitchell study assessed impulsivity in abstinent alcoholics. As such, the impact of abstinence in the Mitchell study could have served to revert those individuals to behavioral states motivated by positive affect, rather than the negative affect-mediated state of acute withdrawal (Walker, 2012). Such a concept is supported by data demonstrating that alcohol-dependent subjects showed reduced inhibitory control compared with healthy controls (Schmaal et al, 2013), and that alcohol dependence-induced phenotypes in humans during withdrawal appear to be correlated with level of physiological withdrawal (Schuckit et al, 1997a,b).

In addition to alcohol reward and reinforcement, alcohol dependence and withdrawal, as well as negative affective behavior and stress-mediated dysphoria, the endogenous opioid peptide system (EOS) appears to have a role in specific cognitive processes relevant to AUDs including craving, decision-making, and impulsivity (Bencherif et al, 2004; Boettiger et al, 2009). In alcoholics, the effects of naltrexone on alcohol cue-induced brain activation, as well as brain regions predictive of immediate reward bias during decision-making, involve the OFC (Myrick et al, 2008; Boettiger et al, 2009). Assessment of mu-opioid receptor (MOR) radiotracer binding using positron emission tomography (PET) has implicated opioid peptide systems within areas such as the dlPFC, OFC, and basolateral amygdala with high impulsiveness and low deliberation scores (Love et al, 2009). Furthermore, also using PET, alcohol-dependent individuals were shown to have lower MOR binding in the dlPFC that was functionally related to alcohol craving (Bencherif et al, 2004) and, of particular interest, was the additional observation that craving and depression were correlated with each other, but negatively correlated with MOR binding. The latter evidence supports assertions that KOR-mediated negative affect promotes dysregulated alcohol intake and the predictions of the Opponent-Process Theory of Motivation (Solomon and Corbit, 1974) for the effects of chronic alcohol on the EOS, although reduced MORs could be a predisposing factor to, rather than a consequence of, alcohol dependence. Other impulse-control disorders, including pathological gambling, may be relieved by opioid antagonists (Kim, 1998), supporting a role for the EOS in impulse-control disorders.

Dysregulation of the EOS may contribute to enhanced impulsivity and reduced regulation of alcohol/drug seeking and consumption, although naltrexone and nalmefene bind to all opioid receptors and may not be producing their effects exclusively through blockade of the MOR, but appear to also be acting through a KOR mechanism (Walker and Koob, 2008). Indeed, KORs have been shown to negatively regulate dopamine, glutamate, GABA, and serotonin transmission through presynaptic mechanisms in areas such as the nucleus accumbens, and these neurotransmitter systems have all been shown to regulate PFC function (see Sirohi et al, 2012 for review). The fact that dissociable effects were observed for U50,488 in the DD and SSRT paradigms is supported by the differential PFC neurobiology for the DD and SSRT paradigms (Winstanley, 2007), as well as the existence of an extra corticothalamostriatal circuit involved in sending the stop response in the SSRT (Duann et al, 2009; Swann et al, 2012) that provide a basis for dissociable effects of KOR activation on impulsive phenotypes. Alcohol dependence has been shown to affect decision-making using rodent models (Badanich et al, 2011), however, its effects remain to be assessed using rodents in tasks such as the SSRT.

In conclusion, the KOR agonist U50,488 was shown to selectively have an impact on impulsive-like performance in the SSRT in a nor-BNI reversible manner, with no effects on DD performance. This identifies a novel therapeutic indication for KOR antagonists and partial agonists (acting as functional antagonists under heighted DYN release) in the treatment of alcohol dependence and neuropsychiatric disorders, with deficits in impulse control related to response inhibition.

\section{FUNDING AND DISCLOSURE}

Dr Walker received funding, in part, by $\mathrm{NIH}$ grant R01AA020394-01 from the National Institute on Alcohol Abuse and Alcoholism and research grants from the WSU Alcohol and Drug Abuse Research Program. The content is solely the responsibility of the authors and does not necessarily represent the official views of the National Institute on Alcohol Abuse and Alcoholism, the National Institutes of Health, or the State of Washington. The authors declare no conflict of interest.

\section{ACKNOWLEDGEMENTS}

The authors acknowledge the contribution of Seth Davis and the members of the Laboratory of Alcoholism and Addiction Neuroscience.

\section{REFERENCES}

Ainslie G (1975). Specious reward: a behavioral theory of impulsiveness and impulse control. Psychol Bull 82: 463-496.

American Psychiatric Association (2000). Diagnostic and Statistical Manual of Mental Disorders DSM-IV-TR. American Psychiatric Association: Washington, DC.

Aragues M, Jurado R, Quinto R, Rubio G (2011). Laboratory paradigms of impulsivity and alcohol dependence: a review. Eur Addict Res 17: 64-71.

Badanich KA, Becker HC, Woodward JJ (2011). Effects of chronic intermittent ethanol exposure on orbitofrontal and medial prefrontal cortex-dependent behaviors in mice. Behav Neurosci 125: 879-891.

Bals-Kubik R, Herz A, Shippenberg TS (1989). Evidence that the aversive effects of opioid antagonists and kappa-agonists are centrally mediated. Psychopharmacology (Berl) 98: 203-206.

Bazov I, Kononenko O, Watanabe H, Kuntic V, Sarkisyan D, Taqi MM et al (2013). The endogenous opioid system in human alcoholics: molecular adaptations in brain areas involved in cognitive control of addiction. Addict Biol 18: 161-169. 
Bencherif B, Wand GS, McCaul ME, Kim YK, Ilgin N, Dannals RF et al (2004). Mu-opioid receptor binding measured by [11C]carfentanil positron emission tomography is related to craving and mood in alcohol dependence. Biol Psychiatry 55: 255-262.

Berger AL, Williams AM, McGinnis MM, Walker BM (2013). Affective cue-induced escalation of alcohol self-administration and increased $22-\mathrm{kHz}$ ultrasonic vocalizations during alcohol withdrawal: role of kappa-opioid receptors. Neuropsychopharmacology 38: 647-654.

Boettiger CA, Kelley EA, Mitchell JM, D’Esposito M, Fields HL (2009). Now or Later? An fMRI study of the effects of endogenous opioid blockade on a decision-making network. Pharmacol Biochem Behav 93: 291-299.

Bruchas MR, Yang T, Schreiber S, Defino M, Kwan SC, Li S et al (2007). Long-acting kappa opioid antagonists disrupt receptor signaling and produce noncompetitive effects by activating c-Jun N-terminal kinase. J Biol Chem 282: 29803-29811.

Cardinal RN (2006). Neural systems implicated in delayed and probabilistic reinforcement. Neural Netw 19: 1277-1301.

Chartoff E, Sawyer A, Rachlin A, Potter D, Pliakas A, Carlezon WA (2012). Blockade of kappa opioid receptors attenuates the development of depressive-like behaviors induced by cocaine withdrawal in rats. Neuropharmacology 62: 167-176.

Crews FT, Boettiger CA (2009). Impulsivity, frontal lobes and risk for addiction. Pharmacol Biochem Behav 93: 237-247.

D'Addario C, Caputi FF, Rimondini R, Gandolfi O, Del BE, Candeletti $S$ et al (2013). Different alcohol exposures induce selective alterations on the expression of dynorphin and nociceptin systems related genes in rat brain. Addict Biol 18: 425-433.

de Wit H (2009). Impulsivity as a determinant and consequence of drug use: a review of underlying processes. Addict Biol 14: 22-31.

Deehan GA Jr, McKinzie DL, Carroll FI, McBride WJ, Rodd ZA (2012). The long-lasting effects of JDTic, a kappa opioid receptor antagonist, on the expression of ethanol-seeking behavior and the relapse drinking of female alcohol-preferring (P) rats. Pharmacol Biochem Behav 101: 581-587.

Dougherty DM, Mathias CW, Marsh-Richard DM, Furr RM, Nouvion SO, Dawes MA (2009). Distinctions in behavioral impulsivity: implications for substance abuse research. Addict Disord Their Treat 8: 61-73.

Duann JR, Ide JS, Luo X, Li CS (2009). Functional connectivity delineates distinct roles of the inferior frontal cortex and presupplementary motor area in stop signal inhibition. J Neurosci 29: 10171-10179.

Eagle DM, Robbins TW (2003a). Inhibitory control in rats performing a stop-signal reaction-time task: effects of lesions of the medial striatum and d-amphetamine. Behav Neurosci 117: 1302-1317.

Eagle DM, Robbins TW (2003b). Lesions of the medial prefrontal cortex or nucleus accumbens core do not impair inhibitory control in rats performing a stop-signal reaction time task. Behav Brain Res 146: 131-144.

Evenden JL, Ryan CN (1996). The pharmacology of impulsive behaviour in rats: the effects of drugs on response choice with varying delays of reinforcement. Psychopharmacology (Berl) 128: 161-170.

Fernandez-Serrano MJ, Perez-Garcia M, Verdejo-Garcia A (2011). What are the specific $v s$ generalized effects of drugs of abuse on neuropsychological performance? Neurosci Biobehav Rev 35: 377-406.

Goldstein M, Brendel G, Tuescher O, Pan H, Epstein J, Beutel M et al (2007). Neural substrates of the interaction of emotional stimulus processing and motor inhibitory control: an emotional linguistic go/no-go fMRI study. Neuroimage 36: 1026-1040.

Grant BF, Harford TC (1995). Comorbidity between DSM-IV alcohol use disorders and major depression: results of a national survey. Drug Alcohol Depend 39: 197-206.
Heilig M, Koob GF (2007). A key role for corticotropin-releasing factor in alcohol dependence. Trends Neurosci 30: 399-406.

Kim SW (1998). Opioid antagonists in the treatment of impulsecontrol disorders. J Clin Psychiatry 59: 159-164.

Kissler JL, Sirohi S, Reis DJ, Jansen HT, Quock RM, Smith DG et al (2013). The one-two punch of alcoholism: role of central amygdala dynorphins/kappa-opioid receptors. Biol Psychiatry pii S0006-3223: 00267-00269.

Knoll AT, Muschamp JW, Sillivan SE, Ferguson D, Dietz DM, Meloni EG et al (2011). Kappa opioid receptor signaling in the basolateral amygdala regulates conditioned fear and anxiety in rats. Biol Psychiatry 70: 425-433.

Land BB, Bruchas MR, Lemos JC, Xu M, Melief EJ, Chavkin C (2008). The dysphoric component of stress is encoded by activation of the dynorphin kappa-opioid system. J Neurosci 28: 407-414.

Love TM, Stohler CS, Zubieta JK (2009). Positron emission tomography measures of endogenous opioid neurotransmission and impulsiveness traits in humans. Arch Gen Psychiatry 66: 1124-1134.

Mague SD, Pliakas AM, Todtenkopf MS, Tomasiewicz HC, Zhang Y, Stevens WC Jr et al (2003). Antidepressant-like effects of kappa-opioid receptor antagonists in the forced swim test in rats. J Pharmacol Exp Ther 305: 323-330.

Mansour A, Fox CA, Meng F, Akil H, Watson SJ (1994). Kappa 1 receptor mRNA distribution in the rat CNS: comparison to kappa receptor binding and prodynorphin mRNA. Mol Cell Neurosci 5: 124-144.

Mansour A, Khachaturian H, Lewis ME, Akil H, Watson SJ (1987). Autoradiographic differentiation of mu, delta, and kappa opioid receptors in the rat forebrain and midbrain. J Neurosci 7: $2445-2464$.

Mazur JE (1989). Theories of probabilistic reinforcement. J Exp Anal Behav 51: 87-99.

Mitchell JM, Fields HL, D'Esposito M, Boettiger CA (2005). Impulsive responding in alcoholics. Alcohol Clin Exp Res 29: 2158-2169.

Myrick H, Anton RF, Li X, Henderson S, Randall PK, Voronin K (2008). Effect of naltrexone and ondansetron on alcohol cueinduced activation of the ventral striatum in alcohol-dependent people. Arch Gen Psychiatry 65: 466-475.

National Research Council (1996). Guide for the Care and Use of Laboratory Animals. National Academy Press: Washington, D.C, USA.

Nealey KA, Smith AW, Davis SM, Smith DG, Walker BM (2011). kappa-opioid receptors are implicated in the increased potency of intra-accumbens nalmefene in ethanol-dependent rats. Neuropharmacology 61: 35-42.

Nemeth CL, Paine TA, Rittiner JE, Beguin C, Carroll FI, Roth BL et al (2010). Role of kappa-opioid receptors in the effects of salvinorin A and ketamine on attention in rats. Psychopharmacology (Berl) 210: 263-274.

Paine TA, Tomasiewicz HC, Zhang K, Carlezon WA Jr (2007). Sensitivity of the five-choice serial reaction time task to the effects of various psychotropic drugs in Sprague-Dawley rats. Biol Psychiatry 62: 687-693.

Paxinos G, Watson C (2007). The Rat Brain in Stereotaxic Coordinates. Elsevier, Academic Press: San Diego.

Pessoa L, Padmala S, Kenzer A, Bauer A (2012). Interactions between cognition and emotion during response inhibition. Emotion 12: 192-197.

Petry NM (2001). Delay discounting of money and alcohol in actively using alcoholics, currently abstinent alcoholics, and controls. Psychopharmacology (Berl) 153: 243-250.

Roberts AJ, Heyser CJ, Cole M, Griffin P, Koob GF (2000). Excessive ethanol drinking following a history of dependence: animal model of allostasis. Neuropsychopharmacology 22: 581-594. 
Roy A, DeJong J, Lamparski D, George T, Linnoila M (1991). Depression among alcoholics. Relationship to clinical and cerebrospinal fluid variables. Arch Gen Psychiatry 48: 428-432.

Sabino V, Cottone P, Blasio A, Iyer MR, Steardo L, Rice KC et al (2011). Activation of sigma-receptors induces binge-like drinking in Sardinian alcohol-preferring rats. Neuropsychopharmacology 36: 1207-1218.

Schmaal L, Joos L, Koeleman M, Veltman DJ, van den Brink W, Goudriaan AE (2013). Effects of modafinil on neural correlates of response inhibition in alcohol-dependent patients. Biol Psychiatry 73: $211-218$.

Schuckit MA, Tipp JE, Bergman M, Reich W, Hesselbrock VM, Smith TL (1997a). Comparison of induced and independent major depressive disorders in 2,945 alcoholics. Am J Psychiatry 154: $948-957$.

Schuckit MA, Tipp JE, Bucholz KK, Nurnberger JI Jr, Hesselbrock VM, Crowe RR et al (1997b). The life-time rates of three major mood disorders and four major anxiety disorders in alcoholics and controls. Addiction 92: 1289-1304.

Sirohi S, Bakalkin G, Walker BM (2012). Alcohol-induced plasticity in the dynorphin/kappa-opioid receptor system. Front $\mathrm{Mol}$ Neurosci 5: 95.

Solomon RL, Corbit JD (1974). An opponent-process theory of motivation. I. Temporal dynamics of affect. Psychol Rev 81: 119-145.

Substance Abuse and Mental Health Services Administration (2005). Results from the 2004 National Survey on Drug Use and Health. Office of Applied Studies, DHHS Publication: Rockville, MD, USA.

Swann NC, Cai W, Conner CR, Pieters TA, Claffey MP, George JS et al (2012). Roles for the pre-supplementary motor area and the right inferior frontal gyrus in stopping action: electrophysiological responses and functional and structural connectivity. Neuroimage 59: 2860-2870.

Todtenkopf MS, Marcus JF, Portoghese PS, Carlezon WA Jr (2004). Effects of kappa-opioid receptor ligands on intracranial selfstimulation in rats. Psychopharmacology (Berl) 172: 463-470.

Walker BM (2012). Conceptualizing withdrawal-induced escalation of alcohol self-administration as a learned, plasticity-dependent process. Alcohol 46: 339-348.

Walker BM, Koob GF (2008). Pharmacological evidence for a motivational role of kappa-opioid systems in ethanol dependence. Neuropsychopharmacology 33: 643-652.

Walker BM, Valdez GR, McLaughlin JP, Bakalkin G (2012). Targeting dynorphin/kappa opioid receptor systems to treat alcohol abuse and dependence. Alcohol 46: 359-370.

Walker BM, Zorrilla EP, Koob GF (2011). Systemic kappa-opioid receptor antagonism by nor-binaltorphimine reduces dependenceinduced excessive alcohol self-administration in rats. Addict Biol 16: $116-119$.

Williams AM, Reis DJ, Powell AS, Neira LJ, Nealey KA, Ziegler CE et al (2012). The effect of intermittent alcohol vapor or pulsatile heroin on somatic and negative affective indices during spontaneous withdrawal in Wistar rats. Psychopharmacology (Berl) 223: 75-88.

Winstanley CA (2007). The orbitofrontal cortex, impulsivity, and addiction: probing orbitofrontal dysfunction at the neural, neurochemical, and molecular level. Ann N Y Acad Sci 1121: 639-655.

Winstanley CA, Eagle DM, Robbins TW (2006). Behavioral models of impulsivity in relation to ADHD: translation between clinical and preclinical studies. Clin Psychol Rev 26: 379-395. 